\title{
Prediction of albuminuria by different blood pressure measurement methods in type 1 diabetes: a pilot study
}

\author{
George S Stergiou ${ }^{1}$, Christina Alamara ${ }^{1}$, Antonis Drakatos ${ }^{2}$, Constantinos J Stefanidis ${ }^{3}$ and Adriani Vazeou ${ }^{4}$
}

In type 1 diabetes, the risk of nephropathy is strongly influenced by the level of blood pressure (BP). Ambulatory BP (ABP) monitoring has revealed an association between disturbed nocturnal BP drop and albuminuria and suggested a role of BP in microalbuminuria development. This study investigated the relationship between the urinary albumin excretion ratio (AER) and home BP (HBP) compared with ABP and clinical BP (CBP) measurements. A total of 50 adolescents and young adults with type 1 diabetes without hypertension or overt proteinuria (mean age $20 \pm 3.8$ (s.d.) years, 21 male) had measurements of CBP ( 3 visits), HBP ( 6 days), 24-h ABP and AER (daytime and nighttime in the same $24 \mathrm{~h}$ with ABP monitoring). AER of $24 \mathrm{~h}$ was correlated with systolic 24-h $(r=0.31)$, daytime $(r=0.33)$ and nighttime ABP $(r=0.36)$, without significant correlation with diastolic ABP, CBP or HBP (systolic or diastolic). Nighttime AER was correlated with $24-\mathrm{h}$ ( $r=0.39 / 0.35$, systolic/diastolic), daytime $(r=0.36 / 0.32)$ and nighttime ABP $(r=0.44 / 0.28)$. HBP was not associated with nighttime AER, but CBP was (diastolic BP only, $r=0.41$ ). No significant correlations were found between daytime AER and BP measurements. The nocturnal BP dip was not associated with any BP value. In non-dippers, nighttime AER showed strong correlations with ABP (24-h: $r=0.45 / 0.42$, systolic/diastolic; daytime: $r=0.46 / 0.45$; nighttime: $r=0.49 / 0.35)$, HBP $(r=0.34 / 0.31)$ and CBP $(r=0.39 / 0.47)$. No such associations were found in dippers $(r=0.05-0.10)$. These preliminary data suggest that in the early stage of diabetes-1, 24-h ABP monitoring seems to be the optimal method of revealing the association between BP and albuminuria, and cannot be replaced by HBP monitoring.

Hypertension Research (2009) 32, 680-684; doi:10.1038/hr.2009.82; published online 5 June 2009

Keywords: ambulatory blood pressure; home blood pressure; microalbuminuria; type 1 diabetes

\section{INTRODUCTION}

In type 1 diabetes, microalbuminuria is regarded as the earliest manifestation of nephropathy and as a marker of increased cardiovascular morbidity. ${ }^{1,2}$ If left untreated, about $80 \%$ of individuals with type 1 diabetes and sustained microalbuminuria will develop overt proteinuria. ${ }^{1-3}$ Hypertension is probably the strongest modifiable risk factor for developing diabetic nephropathy. ${ }^{1-3}$ Moreover, the risk of progression to overt nephropathy is strongly influenced by the level of blood pressure (BP), perhaps more than by the degree of glycemic control. ${ }^{1-3}$

The measurement of BP in the office or clinic is traditionally used for the assessment of hypertension status in diabetic patients. ${ }^{1,2}$ In type 1 diabetes, clinical BP (CBP) is usually normal, even after the development of microalbuminuria. ${ }^{4}$ However, CBP is poorly reproducible and subject to the white coat, the masked and the placebo effect, and to observer bias when the auscultatory technique is used. ${ }^{5}$ On the other hand, 24-h ambulatory $\mathrm{BP}(\mathrm{ABP})$ is more reproducible than are office measurements; it is devoid of the white coat, the masked and the placebo effect, and is more closely associated with target organ damage and cardiovascular disease. ${ }^{5} \mathrm{ABP}$ monitoring in type 1 diabetes revealed an association of disturbed nocturnal BP drop with microalbuminuria and suggested a role of elevated BP in microalbuminuria development. ${ }^{4}$

Self-monitoring of BP by patients at home is being increasingly used as an alternative to ambulatory monitoring for out-of-office BP assessment, and recent guidelines recommend the wide application of this technique in clinical practice. ${ }^{6}$ Home BP (HBP) monitoring shares most of the advantages of ambulatory monitoring and, in addition, has been shown to improve long-term compliance with treatment. ${ }^{6}$

This study was designed to investigate the relationship between albuminuria and HBP compared with $\mathrm{ABP}$ and $\mathrm{CBP}$ in individuals with type 1 diabetes.

\section{METHODS}

Participants

Adolescents and young adults with a diagnosis of type 1 diabetes at least 4 years before study entry were recruited in a prospective study involving measurements of $\mathrm{BP}$ (CBP, HBP and $\mathrm{ABP}$ ) and urinary protein. Exclusion criteria were history of hypertension, treatment with antihypertensive drugs or other agents that might influence BP, overt proteinuria, any serious chronic disease (cardiac, respiratory or kidney failure, malignancy and so on), fever or urinary tract

${ }^{1}$ Third University Department of Medicine, Hypertension Center, Sotiria Hospital, Athens, Greece; ${ }^{2}$ Depatrment of Biochemistry, P\&A Kyriakou Children's Hospital, Athens, Greece; ${ }^{3}$ Department of Nephrology, P\&A Kyriakou Children's Hospital, Athens, Greece and ${ }^{4}$ First Department of Pediatrics, P\&A Kyriakou Children's Hospital, Athens, Greece Correspondence: Professor GS Stergiou, Third University Department of Medicine, Hypertension Center, Sotiria Hospital, 152 Mesogion Avenue, Athens 11527, Greece. E-mail: gstergi@med.uoa.gr

Received 1 December 2008; revised 14 April 2009; accepted 22 April 2009; published online 5 June 2009 
infection. The study protocol was approved by the hospital scientific committee and signed informed consent was obtained from all participants, and from their parents in the case of adolescents.

\section{Measurements}

Home BP was measured on 6 working days within 2 weeks, using validated fully automated electronic (oscillometric) devices, Omron HEM-705CP (stores and prints the last 12 readings) or Omron IC (stores 24 measurements, which can be downloaded to a PC) (Omron Healthcare GmbH, Hamburg, Germany; bladder size $12 \times 23 \mathrm{~cm}$ or $14 \times 28 \mathrm{~cm}$ where appropriate). ${ }^{7}$ Participants were trained on the conditions for HBP monitoring and in the use of the devices and were instructed to take duplicate morning $(0600-1000 \mathrm{~h})$ and evening (1800$2200 \mathrm{~h}$ ) measurements after a 5 min seated rest, with 1 min between measurements. In addition to the device's memory storage and printout, a form was supplied to the participants to report all their HBP readings. For the evaluation of HBP, normalcy values reported by the Arsakeion study ${ }^{8}$ were used for adolescents and the European Society of Hypertension (ESH) thresholds for adults. $^{6}$

Ambulatory BP was measured the day before or after the HBP-monitoring session in random order according to the participants' preference and device availability. Validated oscillometric devices, SpaceLabs 90207 or 90217, were used (SpaceLabs Inc., Redmond, WA, USA, bladder size $12 \times 23 \mathrm{~cm}$ or $9 \times 16 \mathrm{~cm}$ where appropriate). ${ }^{7}$ The recorders were programed to measure BP at $20 \mathrm{~min}$ intervals for $24 \mathrm{~h}$ and were always applied on a routine workday. The individuals were instructed to follow their usual daily activities but to remain still with the forearm extended during each $\mathrm{BP}$ reading and to provide a brief diary specifying the times at which they went to bed and arose. For the evaluation of ABP, normalcy values by Wühl et al. ${ }^{9}$ were used for adolescents and the ESH thresholds for adults. ${ }^{5}$ Nocturnal dipping was defined as a BP drop $>10 \%$ compared with awake values for systolic and/or diastolic BP. ${ }^{5}$ Before each home or ABP-monitoring session, the accuracy of the devices was tested against a standard mercury sphygmomanometer by manual activation (Y-shaped connector; three successive readings).

Clinic BP was measured on three visits within 3 weeks when participants came to receive or bring back the devices for home or $\mathrm{ABP}$ monitoring. Measurements were performed by three physicians who fulfilled the British Hypertension Society protocol criteria for observer agreement in BP measurement. ${ }^{10}$ Triplicate BP measurements were taken at each visit after a 5 min seated rest, with 1 min between recordings, using a standard mercury sphygmomanometer (cuff with bladder size $9 \times 18 \mathrm{~cm}, 12 \times 23 \mathrm{~cm}$ or $15 \times 35 \mathrm{~cm}$, according to arm circumference). For the evaluation of CBP, the 4th Report of the US Task Force on Diagnosis, Evaluation and Treatment of High Blood Pressure in Children and Adolescents ${ }^{11}$ was used for adolescents (hypertension: CBP $\geqslant 95$ th percentile for sex, age and height; prehypertension: BP $\geqslant 90$ th percentile but $<95$ th percentile or $\geqslant 120 / 80 \mathrm{~mm} \mathrm{Hg}$ ). For adults, ESH classification was used. ${ }^{12}$

Urine protein was assessed through a 24 -h sample collected in the same 24-h period with ABP monitoring. Urine collection was performed separately during daytime and nighttime (awake and asleep period of each individual), and the participants reported the exact time that each collection started and ended. Albumin concentration was measured using an immunonephelometric method (Dade Behring BN II nephelometer, Eschborn, Germany) and the albumin excretion ratio (AER) was calculated as $\mu \mathrm{g} \mathrm{min}^{-1}$ for the entire 24 -h period and

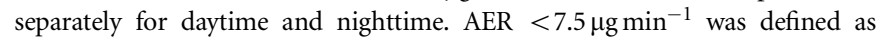
normal, $7.5-20 \mu \mathrm{g} \mathrm{min}^{-1}$ as high-normal ${ }^{2,13,14}$ and $20-200 \mu \mathrm{g} \mathrm{min}^{-1}$ as microalbuminuria. ${ }^{1,3}$ Although albumin concentration measured on the same 24-h period with $\mathrm{ABP}$ monitoring was used for the purpose of this analysis, two additional urine collections were available within the 3 months before or after BP assessment. Thus, patients included in the study subgroup of microalbuminuria were those who had AER $20-200 \mu \mathrm{g} \mathrm{min}^{-1}$ on at least 2 of 3 urine collections.

\section{Analysis}

Ambulatory BP recordings with less than 30 valid awake BP measurements and/or less than 12 asleep measurements were excluded. BP measurements flagged by the software of the monitors as technically erroneous were excluded, as were measurements with systolic $\mathrm{BP}<60$ or $>260 \mathrm{~mm} \mathrm{Hg}$ or with diastolic BP $<40$ or $>150 \mathrm{~mm} \mathrm{Hg}$. Early readings taken less than $20 \mathrm{~min}$ after the monitor was attached to the patient were also excluded, as these were taken in a clinic environment. Average daytime and nighttime ABP levels were calculated according to each individual's reported sleeping hours. Participants who provided less than 12 valid HBP readings or readings taken on less than 4 days were excluded. HBP readings were edited as described above for ABP. All available HBP readings were averaged to obtain the mean value per individual (systolic/diastolic). Morning and evening HBP was also calculated per individual by averaging all the respective measurements, ${ }^{15}$ and the s.d. of all measurements was also calculated as an index of day-to-day HBP variability. ${ }^{16}$ CBP measurements of all three study visits were also averaged to give a single number per individual (systolic/diastolic).

Student's paired $t$-tests were used for the comparison of CBP, HBP and ABP measurements with Bonferroni's correction for multiple comparisons applied where appropriate. Pearson's correlations were used to investigate the association among home, ambulatory and CBP, and of all BP values with AER. AER values were not normally distributed and were therefore log transformed. Statistical analysis was performed using Minitab statistical software (release 13.31; Minitab Inc., State College, PA, USA). A probability value $P<0.05$ was considered to be statistically significant.

\section{RESULTS}

A total of 59 adolescents and young adults were recruited. Eight individuals were excluded because of inadequate data and one because of proteinuria. Data from 50 participants were analyzed. The mean age of all participants was $20 \pm 3.8$ (s.d.) years, 21 (42\%) were male (11 adolescents aged 12-17 years (22\%), 4 males; 22 young adults aged $18-21$ years (44\%), 9 males; 17 adults aged $22-28$ years $(34 \%), 8$ males). The mean body mass index was $23 \pm 2.9 \mathrm{~kg} \mathrm{~m}^{-2}$, the duration of diabetes was $11.9 \pm 3.8$ years and HbAlc was $8.4 \pm 1.8 \%$.

\section{Hypertension status}

On the basis of CBP measurements, none of the adolescents was hypertensive and five were classified as prehypertensives. Two adolescents had elevated ABP and all had low HBP. Seven adults had CBP in the range of stage 1 hypertension, of whom three had low $\mathrm{ABP}$ and the remaining four had low HBP.

\section{Measurements}

The average number of valid HBP readings obtained per participant was $22.6 \pm 1.8$ (range 16-24). An average of $80.8 \pm 5.6$ readings were obtained during 24-h ABP monitoring. A fraction of $15.8 \pm 7.7 \%$ of readings were discarded and $2.5 \pm 3.3 \%$ of time points were not represented in the ABP profile because both the initial and the automatically repeated reading $2 \mathrm{~min}$ later were considered erroneous. The mean difference between parallel test measurements using a mercury column against home monitors was $3.9 \pm 4.6 /$ $3.0 \pm 5.1 \mathrm{~mm} \mathrm{Hg}$ for systolic/diastolic BP. The average CBP, ABP and HBP measurements are presented in Table 1. HBP was lower than CBP and 24-h or daytime ABP (for diastolic BP, significant difference was observed only for daytime BP). CBP was also lower than 24-h or daytime ABP (for diastolic BP, significant difference was observed only for daytime BP). Nighttime BP was lower than all 24-h, daytime ABP, CBP and HBP (not significant for systolic HBP). Fourteen participants were non-dippers (11 only in systolic BP and 3 in systolic and diastolic BP). Non-dippers did not differ from dippers in CBP, HBP, 24-h or daytime BP, but only in systolic nighttime BP (higher in non-dippers, $P<0.05)$.

Forty-one participants (82\%) had 24-h AER $<20 \mu \mathrm{g} \mathrm{min}^{-1}$, and from the remaining nine with $>20 \mu \mathrm{g} \mathrm{min}^{-1}$ (microalbuminuria), in only six was this confirmed in a second assessment before or after the 
Table 1 Measurement of blood pressure and pulse rate in the clinic, at home and with ambulatory monitoring (mean \pm s.d.)

\begin{tabular}{lccc}
\hline Measurement method & Systolic $B P(\mathrm{~mm} \mathrm{Hg})$ & Diastolic BP $(\mathrm{mm} \mathrm{Hg})$ & Pulse rate (beats min $\left.{ }^{-1}\right)$ \\
\hline Clinic & $112.5 \pm 10.4$ & $70.4 \pm 7.3$ & $78.7 \pm 6.6$ \\
Ambulatory & & & $77.8 \pm 8.9$ \\
$24 \mathrm{~h}$ & $116 \pm 10^{* *}$ & $69.4 \pm 5.9$ & $84 \pm 9.7^{*}$ \\
Awake & $121.7 \pm 10.2^{* * *}$ & $75.3 \pm 6.2^{* * *}$ & $66.2 \pm 8.3^{* * *}$ \\
Asleep & $106.5 \pm 9.8$ & $59.4 \pm 6.5^{* * *}$ & $21.0 \pm 6.1$ \\
Night dip & $12.5 \pm 4.6$ & $21.1 \pm 6$ & $78.5 \pm 7.8$ \\
Home & $109 \pm 11.5$ & $68.1 \pm 6.4$ & \\
\hline
\end{tabular}

Abbreviation: $\mathrm{BP}$, blood pressure.

${ }^{*} P<0.05 ;{ }^{*} P<0.01 ;{ }^{* * *} P<0.001, P$ values for comparisons between home and other BP measurements.

study (data obtained from patients' hospital records). Thus, 44 participants were classified as normalbuminuric, with 26 having normal AER $\left(<7.5 \mu \mathrm{g} \mathrm{min}^{-1}\right)$ and 18 having high-normal $\left(>7.5-20 \mu \mathrm{g} \mathrm{min}^{-1}\right)$. In the normal AER subgroup, there were 11 men $(42 \%)$ and in the high-normal subgroup there were nine $(50 \%)$. There was no difference in age, diabetes duration and HBAlc between the normal and the high-normal AER subgroups. There was a consistent trend for clinical, home and ambulatory systolic BP to be higher in participants with high-normal compared with those with normal AER (statistically significant only for nighttime BP, mean difference $6.4 \mathrm{~mm} \mathrm{Hg}, P<0.05)$. These findings were similar when adolescents and young adults were analyzed separately; yet neither nighttime BP reached statistical significance because of small sample sizes.

\section{Blood pressure: albuminuria association}

Twenty-four hour AER was strongly correlated with systolic 24-h ambulatory $(r=0.31, P=0.04)$, daytime $(r=0.33, P=0.03)$ and nighttime $\mathrm{ABP}(r=0.36, P=0.01)$, but there was no significant correlation with ambulatory diastolic BP (24-h $r=0.16$, daytime $r=0.19$, nighttime $r=0.13$, all $P=\mathrm{NS})$, or with clinical $(r=0.24 / 0.24$, systolic/ diastolic, both $P=\mathrm{NS})$ and HBP $(r=0.07 /-0.18$, both $P=\mathrm{NS})$. The relationship of AER average with HBP was not improved when morning and evening HBP measurements were analyzed separately or when the s.d. of mean HBP had been used as an index of day-today HBP variability (all correlations not significant). Nighttime AER was strongly correlated with 24 -h ambulatory $(r=0.39 / 0.35$ for systolic/diastolic, $P=0.01 / 0.02)$, daytime $(r=0.36 / 0.32, P=0.02 / 0.03)$ and nighttime ABP $(r=0.44 / 0.28, P=0.003 / 0.07)$. HBP was not associated with nighttime AER ( $r=0.19 / 0.08$, systolic/diastolic, both $P=\mathrm{NS})$, but CBP was for diastolic BP only $(r=0.41, P=0.006)$. No significant correlations were found between daytime AER and CBP, HBP or ABP. Furthermore, the nocturnal BP dip was not associated with any of the BP measurement methods.

In non-dippers, nighttime AER showed strong correlations with systolic and diastolic ABP (24-h: $r=0.45 / 0.42$, systolic/diastolic; daytime: $r=0.46 / 0.45$; nighttime: $r=0.49 / 0.35)$, with HBP $(r=0.34 / 0.31)$ and also with CBP $(r=0.39 / 0.47)$. Owing to the small sample size $(n=14)$, none of these correlations reached statistical significance, yet no such associations were found in dippers $(n=36, r$ values 0.05-0.10).

\section{DISCUSSION}

This study compared different office and out-of-office BP measurement methods in terms of their relationship with albuminuria in type1 diabetes without hypertension or proteinuria. The main finding is that ABP monitoring seemed to be superior to CBP and also to HBP measurements by providing the strongest relationship with albuminuria.

Regarding the comparison of BP levels obtained by different measurement methods, this study in normotensive adolescents and young adults showed (a) little difference between office and HBP measurements and (b) daytime ABP being significantly higher than home (by 12.7/7.2 mm Hg; $P<0.001$ ) or clinical measurements (by 9.2/4.9 mm Hg; $P<0.001$ ) (Table 1). These findings are in line with a previous study in 778 healthy children and adolescents, which showed little difference between office and HBP measurements. ${ }^{17}$ Furthermore, this study confirms previous reports suggesting that, in contrast to adults in whom HBP levels are similar to those of daytime $\mathrm{ABP},{ }^{6}$ in children and adolescents ${ }^{18-21}$ and in young adults, ${ }^{22}$ daytime BP seems to be significantly higher than that in office and home measurements, probably because of the high level of physical activity during the day in the young population.

The superiority of ABP monitoring compared with conventional clinical measurements in predicting albuminuria is well established. ${ }^{5,12}$ HBP monitoring has several similarities with ambulatory monitoring, mainly because both methods provide multiple measurements in the usual environment of individual patients. ${ }^{6}$ Studies in nondiabetic hypertensives have shown HBP monitoring to be as good as ambulatory monitoring in predicting albuminuria and left ventricular hypertrophy. ${ }^{23-26}$

To our knowledge, no published study provided a direct comparison of home with ABP in terms of their association with albuminuria in type 1 diabetes. It is clear that the development of albuminuria and its relationship with the rise in BP is fundamentally different in type 1 diabetes compared with type $2 .{ }^{4}$ A study in 53 type 1 diabetics showed that nephropathy is more common in individuals with elevated home than $\mathrm{CBP}^{27}$ A study in 50 type 2 diabetics showed HBP to be more predictive of microalbuminuria and proteinuria than $\mathrm{CBP}^{28}$ and another one in elderly type 2 diabetics showed that HBP is as good as $\mathrm{ABP}$ in predicting the progression of albuminuria. ${ }^{29}$ However, when both methods were entered in the same model, HBP lost its significance and nighttime ABP was the only independent predictor of worsening albuminuria. ${ }^{29}$

Previous studies in diabetics ${ }^{30,31}$ and nondiabetics ${ }^{22}$ have shown that nighttime $\mathrm{ABP}$ gives the strongest correlations with albuminuria. This was not confirmed in this study, yet the findings do support the view that $A B P$ is superior to clinical and also to home measurements in predicting albuminuria in type 1 diabetes. Although the crosssectional design is not an appropriate approach to investigate the true association between albuminuria and $\mathrm{BP}$, the fact that measurements of 24-h ABP and albuminuria were performed simultaneously is one 
of the strengths of this study. Furthermore, it should be mentioned that this study examined the relationship between BP and albuminuria at an early stage of the natural history of BP elevation and renal involvement of type 1 diabetes. It might be argued that at a later stage, with elevated BP and more advanced renal injury, the ability of HBP in predicting albuminuria might improve.

The fact that the association of $\mathrm{ABP}$ with albuminuria was entirely attributed to nighttime albuminuria, whereas daytime albuminuria did not yield significant associations, is not a surprise. Interestingly, in non-dippers, but not in dippers, strong correlations were found between nighttime albuminuria and both systolic and diastolic BP, irrespective of the method used for its assessment (ambulatory, home or clinical). These data suggest that when the normal diurnal BP variation has been disrupted (non-dipping pattern), there is a decisive pathophysiological relationship between BP and albuminuria. Nevertheless, this study cannot verify whether a causative relationship exists between the non-dipping pattern and albuminuria. A previous study in 75 adolescents and young adults with type 1 diabetes and normal urinary albumin excretion and BP, followed up for more than 5 years, showed that increased systolic nighttime BP precedes the development of microalbuminuria. ${ }^{4}$ More research is needed on whether antihypertensive therapy specifically targeting nighttime BP might offer additional renal and cardiovascular protection in non-dippers. ${ }^{32,33}$

Owing to the small sample size included in the study, these findings should be considered as preliminary. Moreover, the superiority of ABP in predicting albuminuria in this study might be attributed to the larger number of readings averaged. It might be argued that HBP might be as good as ABP if the same number of readings has been obtained by each method.

In conclusion, these data suggest that in the early stage of type 1 diabetes, 24-h ABP monitoring seems to be the optimal method to reveal the association between $\mathrm{BP}$ and albuminuria, and cannot be replaced by HBP monitoring. More studies are needed to confirm these findings and to investigate the role of HBP monitoring in more advanced stages of type 1 diabetes, for example, with hypertension or proteinuria.

\section{CONFLICT OF INTEREST}

The authors declare no conflict of interest.

1 Gross JL, de Azevedo MJ, Silveiro SP, Canani LH, Caramori ML, Zelmanovitz T. Diabetic nephropathy: diagnosis, prevention, and treatment. Diabetes Care 2005; 28: 164-176.

2 Stone ML, Craig ME, Chan AK, Lee JW, Verge CF, Donaghue KM. Natural history and risk factors for microalbuminuria in adolescents with type 1 diabetes. Diabetes Care 2006; 29: 2072-2077.

3 Microalbuminuria Collaborative Study Group. Intensive therapy and progression to clinical albuminuria in patients with insulin dependent diabetes mellitus and microalbuminuria. BMJ 1995; 311: 973-977.

4 Lurbe E, Redon J, Kesani A, Pascual JM, Tacons J, Alvarez V, Batlle D. Increase in nocturnal blood pressure and progression to microalbuminuria in type 1 diabetes. $N$ Engl J Med 2002; 347: 797-805.

5 O'Brien E, Asmar R, Beilin L, Imai Y, Mancia G, Mengden T, Myers M, Padfield P, Palatini P, Parati G, Pickering T, Redon J, Staessen J, Stergiou G, Verdecchia P. European Society of Hypertension Working Group on Blood Pressure Monitoring. Practice guidelines of the European Society of Hypertension for clinic, ambulatory and self blood pressure measurement. J Hypertens 2005; 23: 697-701.

6 Parati G, Stergiou GS, Asmar R, Bilo G, de Leeuw P, Imai Y, Kario K, Lurbe E, Manolis A, Mengden T, O'Brien E, Ohkubo T, Padfield P, Palatini P, Pickering T, Redon J, Revera M, Ruilope LM, Shennan A, Staessen JA, Tisler A, Waeber B, Zanchetti A, Mancia G. ESH Working Group on Blood Pressure Monitoring. European Society of Hypertension guidelines for blood pressure monitoring at home: a summary report of the Second
International Consensus Conference on Home Blood Pressure Monitoring. $J$ Hypertens 2008; 26: 1505-1526.

7 dabl $\mathbb{R}$ Educational Trust: Devices for blood pressure measurement. http://www.dableducational.org. Accessed 28 November 2008.

8 Stergiou GS, Yiannes NG, Rarra VC, Panagiotakos DB. Home blood pressure normalcy in children and adolescents: the Arsakeion School study. J Hypertens 2007; 25: 1375-1379.

9 Wühl E, Witte K, Soergel M, Mehls O, Schaefer F. German Working Group on Pediatric Hypertension. Distribution of 24-h ambulatory blood pressure in children: normalized reference values and role of body dimensions. J Hypertens 2002; 20: 1995-2007.

10 O'Brien E, Petrie J, Littler W, de Swiet M, Padfield PL, O'Malley K, Jamieson M, Altman $\mathrm{D}$, Bland M, Atkins N. The British Hypertension Society protocol for the evaluation of automated and semi-automated blood pressure measuring devices with special reference to ambulatory systems. J Hypertens 1990; 8: 607-619.

11 The Fourth Report on the Diagnosis, Evaluation, Treatment of High Blood Pressure in Children and Adolescents. National High Blood Pressure Education Program Working Group on High Blood Pressure in Children and Adolescents. Pediatrics 2004; 114: 555-576.

12 Mancia G, De Backer G, Dominiczak A, Cifkova R, Fagard R, Germano G, Grassi G, Heagerty AM, Kjeldsen SE, Laurent S, Narkiewicz K, Ruilope L, Rynkiewicz A, Schmieder RE, Boudier HA, Zanchetti A, Vahanian A, Camm J, De Caterina R, Dean V, Dickstein K, Filippatos G, Funck-Brentano C, Hellemans I, Kristensen SD, McGregor K, Sechtem U, Silber S, Tendera M, Widimsky P, Zamorano JL, Erdine S, Kiowski W, Agabiti-Rosei E, Ambrosioni E, Lindholm LH, Viigimaa M, Adamopoulos S, AgabitiRosei E, Ambrosioni E, Bertomeu V, Clement D, Erdine S, Farsang C, Gaita D, Lip G, Mallion JM, Manolis AJ, Nilsson PM, O'Brien E, Ponikowski P, Redon J, Ruschitzka F, Tamargo J, van Zwieten P, Waeber B, Williams B. Management of Arterial Hypertension of the European Society of Hypertension; European Society of Cardiology. 2007 Guidelines for the Management of Arterial Hypertension: The Task Force for the Management of Arterial Hypertension of the European Society of Hypertension (ESH) and of the European Society of Cardiology (ESC). J Hypertens 2007; 25: 1105-1187.

13 Couper JJ, Staples AJ, Cocciolone R, Nairn J, Badcock N, Henning P. Relationship of smoking and albuminuria in children with insulin-dependent diabetes. Diabet Med 1994; 11: 666-669.

14 Chase PH, Marshall G, Garg SK, Harris S, Osberg I. Borderline increases in albumin excretion rate and the relation to glycemic control in subjects with type 1 diabetes. Clin Chem 1991; 37: 2048-2052.

15 Imai Y, Otsuka K, Kawano Y, Shimada K, Hayashi H, Tochikubo O, Miyakawa M, Fukiyama K. Japanese Society of Hypertension (JSH) guidelines for self-monitoring of blood pressure at home. Hypertens Res 2003; 26: 771-782.

16 Kikuya M, Ohkubo T, Metoki H, Asayama K, Hara A, Obara T, Inoue R, Hoshi H, Hashimoto J, Totsune K, Satoh H, Imai Y. Day-by-day variability of blood pressure and heart rate at home as a novel predictor of prognosis: the Ohasama study. Hypertension 2008; 52: 1045-1050.

17 Stergiou GS, Yiannes NG, Rarra VC, Panagiotakos DB. Home blood pressure normalcy in children and adolescents: the Arsakeion School study. J Hypertens 2007; 25: 1375-1379.

18 Koch VH, Colli A, Saito MI, Furusawa EA, Ignes E, Okay Y, Mion Júnior D. Comparison between casual blood pressure and ambulatory blood pressure monitoring parameters in healthy and hypertensive adolescents. Blood Press Monit 2000; 5: 281-289.

19 Stergiou GS, Alamara CV, Kalkana CB, Vaindirlis IN, Stefanidis CJ, Dacou-Voutetakis C, Mountokalakis TD. Out-of-office blood pressure in children and adolescents: disparate findings by using home or ambulatory monitoring. Am J Hypertens 2004; 17: 869-875.

20 Wühl E, Hadtstein C, Mehls O, Schaefer F. Escape Trial Group. Home, clinic, and ambulatory blood pressure monitoring in children with chronic renal failure. Pediatr Resg 2004; 55: 492-497.

21 Stergiou GS, Nasothimiou E, Giovas P, Kapoyiannis A, Vazeou A. Diagnosis of hypertension in children and adolescents based on home versus ambulatory blood pressure monitoring. J Hypertens 2008; 26: 1556-1562.

22 Pickering TG, Gerin W, Schwartz JE, Spruill TM, Davidson KW. Franz Volhard lecture: should doctors still measure blood pressure? The missing patients with masked hypertension. J Hypertens 2008; 26: 2259-2267.

23 Stergiou GS, Argyraki KK, Moyssakis I, Mastorantonakis SE, Achimastos AD, Karamanos VG, Roussias LG. Home blood pressure is as reliable as ambulatory blood pressure in predicting target-organ damage in hypertension. Am J Hypertens 2007; 20: 616-621.

24 Shimbo D, Pickering TG, Spruill TM, Abraham D, Schwartz JE, Gerin W. Relative utility of home, ambulatory, and office blood pressures in the prediction of end-organ damage. Am J Hypertens 2007; 20: 476-482.

25 Niiranen TJ, Jula AM, Kantola IM, Karanko H, Reunanen A. Home-measured blood pressure is more strongly associated with electrocardiographic left ventricular hypertrophy than is clinic blood pressure: the Finn-HOME study. J Hum Hypertens 2007; 21: 788-794.

26 Martínez MA, Sancho T, García P, Moreno P, Rubio JM, Palau FJ, Antón JL, Cirujano FJ, Sanz J, Puig JG. MAPA Working Group. Home blood pressure in poorly controlled hypertension: relationship with ambulatory blood pressure and organ damage. Blood Press Monit 2006; 11: 207-213.

27 Kamoi K, Imamura Y, Miyakoshi M, Kobayashi C. Usefulness of home blood pressure measurement in the morning in type 1 diabetic patients. Diabetes Care 2003; 26 : 2473-2475. 
28 Kamoi K, Ikarashi T. The bedtime administration of doxazosin controls morning hypertension and albuminuria in patients with type-2 diabetes: evaluation using home-based blood pressure measurements. Clin Exp Hypertens 2005; 27: 369-376.

29 Palmas W, Pickering TG, Teresi J, Schwartz JE, Field L, Weinstock RS, Shea S. Telemedicine home blood pressure measurements and progression of albuminuria in elderly people with diabetes. Hypertension 2008; 51: 1282-1288.

30 Poulsen PL, Ebbehoj K, Hansen KW, Mogensen CE. 24-h blood pressure and autonomic function is related to albumin excretion within the normoalbuminuric range in IDDM patients. Diabetologia 1997; 40: 718-725.
31 Lurbe A, Redon J, Pascual JM, Tacons J, Alvarez V, Batlle DC. Altered blood pressure during sleep in normotensive subjects with type 1 diabetes. Hypertension 1993; 21 : 227-235.

32 Stergiou GS, Mountokalakis TD. Detection of non-dipper hypertensives in clinical practice: does it really matter? Nephrol Dial Transplant 1999; 14: 2969-2970.

33 Stergiou GS, Nasothimiou EG. Does dosing antihypertensive drugs at night alter renal or cardiovascular outcome: do we have the evidence? Curr Opin Nephrol Hypertens 2008; 17: 464-469. 